\title{
A Novel Advanced Bipolar Tissue Sealer Provides Improved Hemostasis and Less Thermal Damage
}

\author{
Mary Mootoo, John F Cummings, Geisa Paulin-Curlee, Gregory A Trees, Scot Harris, Jeffrey W Clymer*, Joseph F Amaral \\ Ethicon, Inc., Cincinnati, OH, USA
}

\begin{abstract}
Background: Advanced bipolar devices are increasingly popular for cutting and coagulating vessels up to $7 \mathrm{~mm}$ in diameter. In this study, a recently introduced device with improved ergonomics, the ENSEAL ${ }^{\circledR}$ X1 Large Jaw (X1) was compared to another commercially-available advanced bipolar device.

Methods: Ex vivo comparisons included jaw temperature after use and burst pressures of sealed vessels. In vivo acute and survival (30-day) studies in a porcine model evaluated hemostasis at initial sealing and after a simulated hypertensive crisis. Secondary endpoints included tissue sticking, thermal damage, adhesions and hemostasis at the distal tip of the end effector.

Results: Both devices produced burst pressures that were supra-physiological with high rates of in vivo hemostasis both initially and after a blood pressure challenge. X1 showed significantly lower jaw temperatures after use, produced $41 \%$ less thermal damage and $88 \%$ greater hemostasis at the distal tip in deep mesentery.

Conclusions: In these ex vivo and in vivo tests, advanced bipolar devices were shown to be reliable in sealing vessels over a range of sizes and vessel types. The novel design of X1 showed improved temperature control, thermal damage and hemostasis under difficult-to-access conditions. Clinical studies are needed to confirm these results.
\end{abstract}

\section{Introduction}

The use of advanced bipolar instruments for ligation and division of vessels has been steadily increasing in recent years [1]. Devices such as the ENSEAL G2 Super Jaw Tissue Sealer are dedicated bipolar electrosurgical instruments intended for use during open surgery to divide and seal vessels, and cut, grasp and dissect tissue during surgery. These devices are cleared for soft tissue coagulation and are used in a wide variety of general, gynecologic, urologic, thoracic, and vascular procedures. The devices can be used to seal vessels (arteries, veins, lymphatics) up to and including $7 \mathrm{~mm}$ in diameter.

A new version of the ENSEAL device, the ENSEAL ${ }^{\circ} 1$ Large Jaw (X1, Figure 1) was recently developed to offer improved ergonomics and usability, while maintaining reliable sealing characteristics. As with previous versions of ENSEAL, coagulation of tissues is achieved via the application of bipolar electrosurgery to compressed tissue. The jaws are

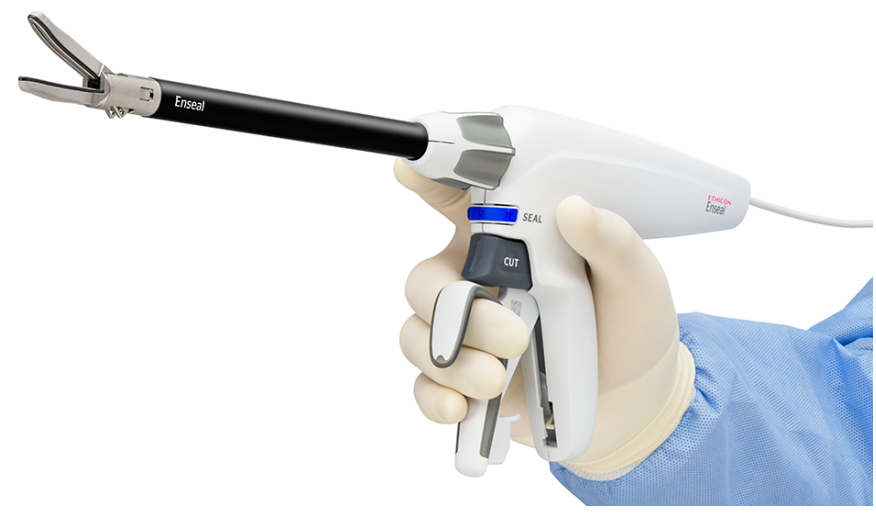

Figure 1. The ENSEAL ${ }^{\circledR}$ X1 Large Jaw Tissue Sealer. also designed for grasping and holding targeted tissue when clamped. Adaptive Tissue Technology ${ }^{\text {max }}$, an advanced algorithm for intelligent and efficient energy delivery, senses and responds to changes in tissue impedance throughout the entire sealing cycle and responds with the optimal amount of energy for secure sealing with minimal thermal damage. When the necessary sensing criteria have been met, an audible tone confirms completion of the sealing cycle. An ergonomic pistol grip housing allows for manual closure of the X1 jaw, and provides both audible and tactile feedback, indicating the jaws have been fully closed and/or opened. The shaft rotates 360 degrees permitting access to difficult-to-reach areas, and allows the user to control the rotation of the shaft with the same hand that operates the device.

This study was undertaken to compare the new X1 to another commercially-available advanced bipolar energy device, the LigaSure Impact $^{\mathrm{m} u}$ Open Instrument (LI). Ex vivo comparisons included jaw temperature after repeated applications and burst pressures, while in vivo evaluation included acute and survival studies of vessel sealing in porcine models, with measures of hemostasis both initially and after a simulated hypertensive crisis, thermal damage, tissue sticking, adhesion formation, and hemostasis at the distal tip of the end effector.

\section{Methods}

The devices used in this study were the $\mathrm{ENSEAL}^{\circ} \mathrm{X} 1$ Large Jaw (X1, Product Code NSLX120L, Ethicon, Inc., Cincinnati OH) and LigaSure

Correspondence to: Jeffrey W Clymer, Ethicon Inc., 4545 Creek Rd, Cincinnati OH 45242, Tel: 513-337-3318; E-mail: jclymer@its.jnj.com

Key words: advanced bipolar, Enseal, vessel sealing, thermal damage, hemostasis

Received: July 20, 2017; Accepted: July 26, 2017; Published: July 28, 2017 
Impact $^{\text {th }}$ Open Instrument (LI, Product Code LF4318, Medtronic Minneapolis MN).

\section{Ex vivo measurements}

Geometric measurements of the devices were performed using calibrated digital calipers. Temperature increase during application was measured using an infrared camera (FLIR A655 IR Camera, FLIR Systems, Wilsonville OR) after covering the jaws with an emissive black paint. Porcine mesentery or jejunum tissue was cut into strips and the devices were fired on the strips per standard generator settings. Infrared video of the jaw was captured for 60 seconds after firing. For both X1 and LI, 10 firings were performed on two devices for both mesentery and jejunum allowing the jaws to cool for at least one minute and wiping with a saline-soaked cloth between firings. The increase of the maximum temperature recorded relative to the initial temperature was used in the analysis.

Burst pressures were measured on three sizes of porcine arteries; small thyrocervical $(<4.0 \mathrm{~mm})$, medium carotid $(4.0-<6.0 \mathrm{~mm})$ and large carotid (6.0-7.5 mm). For each device, 60 seals were made for each size of vessel without tension on the vessel or instrument, and without infusion of the vessel. Vessel diameter was measured in the round (physiologic pressure) state. Measurements were made by infusing saline at a constant rate and monitoring the pressure at which leakage occurred.

\section{In vivo measurements}

All animals and in vivo procedures were approved by an Institutional Animal Care and Use Committee. Comparisons were performed in both acute and survival porcine models.

\section{Acute study procedure}

Using a standard telazol/xylazine anesthetic procedure, pigs were placed in dorsal recumbency. An arterial catheter was placed to directly monitor blood pressure throughout the procedures. The systolic blood pressure was kept above $80 \mathrm{mmHg}$ during surgery. The intra-abdominal vessel and vessel pedicle transections were performed through a ventral midline laparotomy. A total of 34 vessels and vessel pedicles of diameter $7 \mathrm{~mm}$ or less were sealed and transected with each device. Vessels included the inferior mesenteric artery, pancreaticduodenal pedicle, gastroepiploic pedicle, short gastric pedicle, ovarian pedicle, splenic vein, splenic artery and carotid artery. Each seal was assessed for first-pass (initial) hemostasis, and hemostasis during blood pressure challenge, i.e., a simulated hypertensive crisis in which the blood pressure is elevated to at least $200 \mathrm{mmHg}$ with phenylephrine for a 10-minute period. Energy activation time and tissue sticking were monitored.

The transected porcine carotid artery seals (cranial and caudal aspect) were harvested for measurement of the maximum lateral thermal damage via histology (Figure 2). Carotid seals were midline sectioned along the vessel's long axis and perpendicular to the sealed edge and paraffin embedded. Tissues sections approximately 5 microns thick were then mounted on glass slides and stained with hematoxylin and eosin (H\&E) stain. Adventitial collagen denaturation length (lateral thermal damage) measurement began at the proximal edge of sealing device placement to the distant edge of any adventitial collagen denaturation extending radially and was performed on the top and bottom aspect of each seal. Slides were evaluated using routine light microscopy with the pathologist blinded to treatment groups. The maximum value for the top and bottom of the seal was used in the analysis for each aspect of the 8 seals per device.

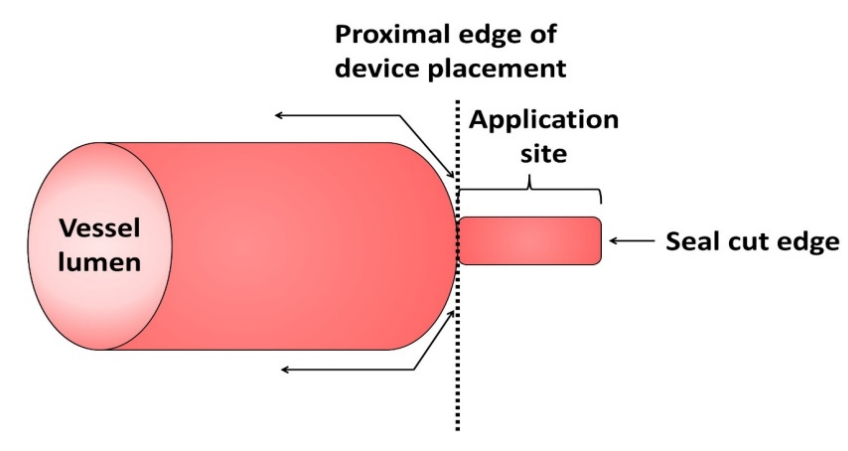

Figure 2. Seal anatomy and site for measuring lateral thermal damage/collagen denaturation along the tunica adventitia (double arrows) on the top and bottom portions of the seal.

\section{Survival study procedure}

Surgery was initiated with a combination of butorphanol/ midazolam/xylazine. After a midline laparotomy, the tail of the spleen was exteriorized and the omental attachments were transected until the gastroepiploic pedicle was reached and the pedicle was transected. Additional omental attachments were transected continuing toward the head of the spleen. The short gastric pedicles were transected, and after isolating the splenic artery from the splenic vein, both were transected. Additional omental and connective tissue attachments to the spleen were transected and the spleen was removed and discarded. After the completion of the splenectomy procedure, a carotid artery was exposed and skeletonized, and the vessel was transected. Hemostasis was evaluated after each transection on a total of 36 vessels/pedicles per device.

The incisions were closed using standard surgical technique with appropriate sutures and/or staples. Tissue glue or tapes were also used to close the skin incision. Carprofen and maropitant were administered for up to 3 days post-operatively, and amoxicillin/ clavulanate was administered for 7 days post-operatively. Immediately prior to euthanasia at 30-32 days post-operatively, vessel/vessel pedicle seal integrity was challenged with the pig under general anesthesia using phenylephrine as a vasopressor to increase the blood pressure, simulating an acute hypertensive crisis. An arterial catheter was placed to directly monitor blood pressure. The phenylephrine was titrated intravenously using a fluid pump to increase the systolic blood pressure to at least $200 \mathrm{mmHg}$ for a period of at least 10 minutes. Following completion of the simulated acute hypertensive crisis, the animal was euthanized, and all vessels/vessel pedicles that were sealed during the splenectomy procedure and carotid artery seals were assessed for chronic seal durability and the presence of tissue adhesions surrounding the seals during necropsy. Chronic seal durability was graded as yes or no, with yes indicating that vessels/vessel pedicles remained hemostatic throughout the post-operative time frame and no indicating that vessels/vessel pedicles did not remain hemostatic. The presence of tissue adhesions surrounding the seal was graded according to the following criteria:

\begin{tabular}{|l|l|}
\hline Adhesion Grading Scale & Description of Adhesion \\
\hline 0 & No adhesion \\
\hline 1 & Localized area with thin adhesions \\
\hline 2 & Localized area with thick adhesions bands \\
\hline 3 & Multifocal areas with thick adhesion bands \\
\hline 4 & $\begin{array}{l}\text { Extensive thick adhesion bands with the surrounding } \\
\text { tissue including between viscera and/or abdominal wall }\end{array}$ \\
\hline
\end{tabular}




\section{Distal tip hemostasis evaluation}

To evaluate hemostasis at the distal tip of the end effector, sealing and transection was performed at the base of porcine mesentery, adjacent to the lymph nodes. The density of the vessels in the thick base of the mesentery tissues does not allow the operator to visibly place individual vessels completely within the jaws of the device. Therefore, insufficient electrode area and compression force will result in bleeding at the distal tip. A total of 54 applications of each device were performed across 4 pigs. Hemostasis and tissue sticking were evaluated for each application. Hemostasis was analyzed on a pass/fail basis. Tissue sticking was rated as none, mild (manipulation of device allowed for release of tissue) or severe (another instrument was used to remove tissue). For data analysis, mild and severe sticking were grouped together, so the result was a dichotomous sticking/no sticking.

\section{Statistical analysis}

Continuous variables were compared between devices via parametric tests (Student's t-test or ANOVA) or via a non-parametric test (Mann-Whitney) if the distribution of data was highly non-normal or skewed. For dichotomous variables, Fisher's exact test was used. An alpha value of 0.05 was taken as the level of statistical significance.

\section{Results}

$\mathrm{X} 1$ and LI have similar jaw length, cut length, jaw width and shaft length (Table 1). Only one side of the jaw of X1 opens, whereas both sides of LI move. The shaft of X1 rotates a full $360^{\circ}$ (i.e., continuously) in contrast to the LI shaft which can only rotate $180^{\circ}$. The length of electrode beyond the knife, i.e., the area where a seal can extend beyond the cutline, is $0.66 \mathrm{~mm}$ greater for $\mathrm{X} 1$ than LI.

In both jejunum and mesentery, the increase in temperature, $\Delta \mathrm{T}$, after application was significantly less for X1 than LI at both the bottom and top jaw by 3.2 to $6.4{ }^{\circ} \mathrm{C}$ (Table 2, Figure 3). The increase in temperature after application was greater for both devices in jejunum than mesentery, and greater for the bottom jaw than the top jaw. Over all vessel sizes tested, there was not a statistically significant difference in burst pressures between X1 and LI. For each of the arterial vessel size groups, the test had an $80 \%$ power to detect a difference in burst pressure of approximately $180 \mathrm{mmHg}$.

In the acute and survival porcine studies (Table 3), there were no significant differences in vessel sizes used, the energy application time, and the rates of first-pass hemostasis or hemostasis during simulated hypertensive crisis. In the acute study, X1 had significantly less tissue sticking and $41 \%$ less thermal damage than LI (Figure 4 ). In the survival study, X1 had significantly less sticking than LI, whereas the adhesion scores were not statistically significantly different. During distal tip sealing in mesentery $\mathrm{X} 1$ was $88 \%$ more hemostatic than LI (Figure 5), while not exhibiting significantly less tissue sticking.

Table 1. Comparisons of physical characteristics between X1 and LI.

\begin{tabular}{|l|l|l|}
\hline Measure & X1 & LI \\
\hline Jaw Length & $38 \mathrm{~mm}$ & $36 \mathrm{~mm}$ \\
\hline Cut Length & $33.5 \mathrm{~mm}$ & $34 \mathrm{~mm}$ \\
\hline Jaw Width & $6 \mathrm{~mm}$ & $6 \mathrm{~mm}$ \\
\hline Shaft Length & $20 \mathrm{~cm}$ & $18 \mathrm{~cm}$ \\
\hline Jaw Aperture & $\begin{array}{l}30.6^{\circ} \\
\text { (unilateral) }\end{array}$ & $\begin{array}{l}27^{\circ} \\
\text { (bilateral) }\end{array}$ \\
\hline Rotation of Shaft & $\begin{array}{l}360^{\circ} \\
\text { (continuous) }\end{array}$ & $180^{\circ}$ \\
\hline $\begin{array}{l}\text { Length of electrode beyond } \\
\text { knife }\end{array}$ & $1.07 \mathrm{~mm}$ & $0.41 \mathrm{~mm}$ \\
\hline
\end{tabular}

Table 2. Benchtop comparisons of X1 and LI.

\begin{tabular}{|c|c|c|c|c|}
\hline Measure & X1 & LI & Statistical Test & p-value \\
\hline $\begin{array}{l}\text { Jejunum } \Delta \mathrm{T} \\
\text { Bottom Jaw } \\
\text { Top Jaw } \\
\text { Mesentery } \Delta \mathrm{T} \\
\text { Bottom Jaw } \\
\text { Top Jaw }\end{array}$ & $\begin{array}{l}n=20 \\
+21.1 \pm 3.8^{\circ} \mathrm{C} \\
+18.6 \pm 3.5^{\circ} \mathrm{C} \\
+17.0^{\circ} \mathrm{C} \\
\text { (median) } \\
+15.0 \pm 3.7^{\circ} \mathrm{C}\end{array}$ & $\begin{array}{l}n=20 \\
+25.9 \pm 2.7^{\circ} \mathrm{C} \\
+25.0 \pm 2.3^{\circ} \mathrm{C} \\
+20.2^{\circ} \mathrm{C} \\
\text { (median) } \\
+19.6 \pm 5.8^{\circ} \mathrm{C}\end{array}$ & $\begin{array}{l}\text { Student's t-test } \\
\text { Student's t-test } \\
\text { Mann-Whitney } \\
\text { Student's t-test }\end{array}$ & $\begin{array}{l}<0.001 \\
<0.001 \\
\\
0.006 \\
0.003\end{array}$ \\
\hline $\begin{array}{l}\text { Jejunum Max T } \\
\text { Bottom Jaw } \\
\text { Top Jaw } \\
\text { Mesentery } \\
\text { Max T } \\
\text { Bottom Jaw } \\
\text { Top Jaw } \\
\end{array}$ & $\begin{array}{l}42.1^{\circ} \mathrm{C} \\
39.6^{\circ} \mathrm{C} \\
38.0^{\circ} \mathrm{C} \\
36.0^{\circ} \mathrm{C}\end{array}$ & $\begin{array}{l}46.9^{\circ} \mathrm{C} \\
46.0^{\circ} \mathrm{C} \\
41.2^{\circ} \mathrm{C} \\
40.6^{\circ} \mathrm{C}\end{array}$ & - & - \\
\hline $\begin{array}{l}\text { Burst Pressure } \\
\text { by vessel } \\
\text { diameter } \\
<4.0 \mathrm{~mm} \\
4.0 \text { to }<6.0 \mathrm{~mm} \\
6.0 \text { to } 7.5 \mathrm{~mm}^{*}\end{array}$ & $\begin{array}{l}n=60 \\
792 \pm 315 \mathrm{mmHg} \\
957 \pm 360 \mathrm{mmHg} \\
851 \pm 410 \mathrm{mmHg}\end{array}$ & $\begin{array}{l}n=60 \\
755 \pm 345 \mathrm{mmHg} \\
1040 \pm 295 \mathrm{mmHg} \\
888 \pm 373 \mathrm{mmHg}\end{array}$ & $\begin{array}{l}\text { Student's t-test } \\
\text { Student's t-test } \\
\text { Student's t-test }\end{array}$ & $\begin{array}{l}0.534 \\
0.169 \\
0.610\end{array}$ \\
\hline
\end{tabular}

*The Advanced Bipolar devices used here are cleared for use in sealing vessels up to and including $7 \mathrm{~mm}$ in diameter.

Table 3. In vivo comparisons of $\mathrm{X} 1$ and LI.

\begin{tabular}{|c|c|c|c|c|}
\hline Measure & $\mathbf{X} 1$ & LI & Statistical Test & p-value \\
\hline \multicolumn{5}{|l|}{ Acute } \\
\hline $\begin{array}{l}\text { Vessel Size } \\
\text { Median }\end{array}$ & $\begin{array}{l}1-7 \mathrm{~mm} \\
5.0 \mathrm{~mm}\end{array}$ & $\begin{array}{l}2-7 \mathrm{~mm} \\
5.0 \mathrm{~mm}\end{array}$ & Mann-Whitney & 0.885 \\
\hline $\begin{array}{l}\text { Energy Application } \\
\text { Time }\end{array}$ & $4.2 \pm 0.5 \mathrm{~s}$ & $4.1 \pm 0.7 \mathrm{~s}$ & Student's t-test & 0.501 \\
\hline Tissue Sticking & $\begin{array}{l}5 / 34 \\
(15 \%)\end{array}$ & $\begin{array}{l}16 / 34 \\
(47 \%)\end{array}$ & Fisher's Exact & 0.008 \\
\hline First-pass hemostasis & $\begin{array}{l}34 / 34 \\
(100 \%)\end{array}$ & $\begin{array}{l}34 / 34 \\
(100 \%)\end{array}$ & Fisher's Exact & 1.000 \\
\hline $\begin{array}{l}\text { Hemostasis at } \\
\text { Challenge }\end{array}$ & $\begin{array}{l}34 / 34 \\
(100 \%)\end{array}$ & $\begin{array}{l}33 / 34 \\
(97 \%)\end{array}$ & Fisher's Exact & 1.000 \\
\hline Thermal Damage & $1.57 \mathrm{~mm}$ & $2.66 \mathrm{~mm}$ & Student's t-test & 0.005 \\
\hline \multicolumn{5}{|l|}{ Survival } \\
\hline $\begin{array}{l}\text { Vessel Size } \\
\text { Range } \\
\text { Median } \\
\end{array}$ & $\begin{array}{l}3-7 \mathrm{~mm} \\
6.0 \mathrm{~mm}\end{array}$ & $\begin{array}{l}2-7 \mathrm{~mm} \\
6.0 \mathrm{~mm}\end{array}$ & Mann-Whitney & 0.395 \\
\hline $\begin{array}{l}\text { Energy Application } \\
\text { Time }\end{array}$ & $4.2 \pm 0.6 \mathrm{~s}$ & $4.1 \pm 1.0$ & Student's t-test & 0.876 \\
\hline Tissue Sticking & $\begin{array}{l}2 / 36 \\
(6 \%)\end{array}$ & $\begin{array}{l}12 / 36 \\
(33 \%)\end{array}$ & Fisher's Exact & 0.006 \\
\hline First-pass Hemostasis & $\begin{array}{l}36 / 36 \\
(100.0 \%)\end{array}$ & $\begin{array}{l}35 / 36 \\
(97 \%)\end{array}$ & Fisher's Exact & 1.000 \\
\hline $\begin{array}{l}\text { Hemostasis during } \\
\text { chronic seal durability }\end{array}$ & $\begin{array}{l}36 / 36 \\
(100 \%)\end{array}$ & $\begin{array}{l}35 / 35 \\
(100 \%)\end{array}$ & Fisher's Exact & 1.000 \\
\hline $\begin{array}{l}\text { Adhesion Score } \\
\text { Median } \\
\text { Range }\end{array}$ & $\begin{array}{l}1 \\
0-2\end{array}$ & $\begin{array}{l}1 \\
0-3\end{array}$ & Mann-Whitney & 0.259 \\
\hline \multicolumn{5}{|l|}{ Distal Tip Sealing } \\
\hline $\begin{array}{l}\text { Hemostasis at Distal } \\
\text { Tip }\end{array}$ & $\begin{array}{l}47 / 54 \\
(87 \%)\end{array}$ & $\begin{array}{l}25 / 54 \\
(46 \%)\end{array}$ & Fisher's Exact & $<0.001$ \\
\hline Sticking & $\begin{array}{l}23 / 54 \\
(43 \%)\end{array}$ & $\begin{array}{l}34 / 54 \\
(63 \%)\end{array}$ & Fisher's Exact & 0.053 \\
\hline
\end{tabular}

Table 4. Finger reach for smallest female and largest male and corresponding required reach for X1.

\begin{tabular}{|l|l|l|l|l|}
\hline Finger & $\begin{array}{l}\mathbf{9 5 \%} \text { smallest } \\
\text { female }\end{array}$ & $\begin{array}{l}\mathbf{9 5 \%} \text { largest } \\
\text { male }\end{array}$ & X1 Control & Required reach \\
\hline Index Finger & $6.9 \mathrm{~cm}$ & $7.9 \mathrm{~cm}$ & $\begin{array}{l}\text { Rotation Knob } \\
\text { Seal/Cut }\end{array}$ & $6.4 \mathrm{~cm}$ \\
$6.1 \mathrm{~cm}$ \\
\hline Middle Finger & $7.4 \mathrm{~cm}$ & $8.6 \mathrm{~cm}$ & Upper Grip & $5.8 \mathrm{~cm}$ \\
\hline Ring Finger & $6.6 \mathrm{~cm}$ & $7.7 \mathrm{~cm}$ & Middle Grip & $6.6 \mathrm{~cm}$ \\
\hline
\end{tabular}




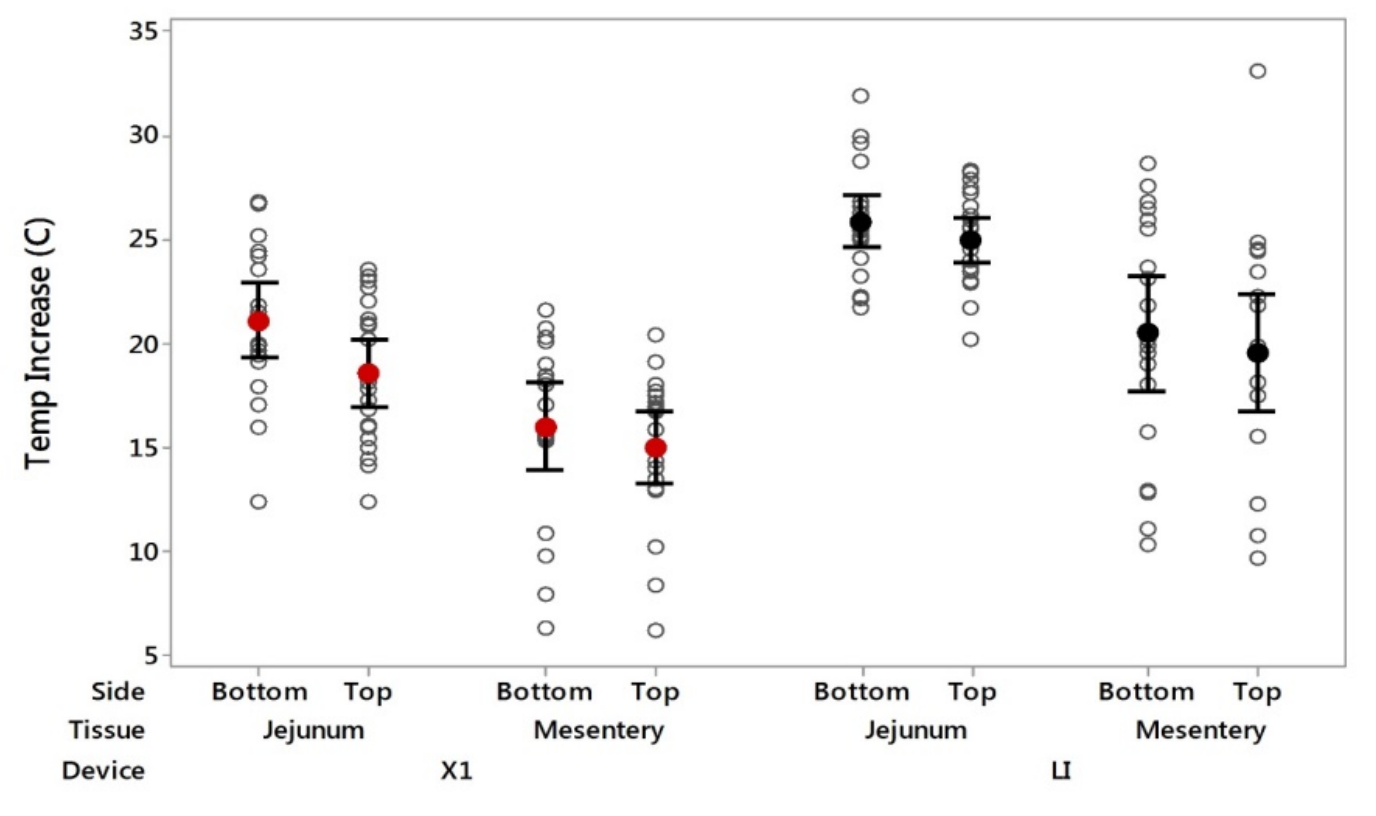

Figure 3. Temperature increase of top and bottom jaws after application of X1 and LI in jejunum and mesentery.

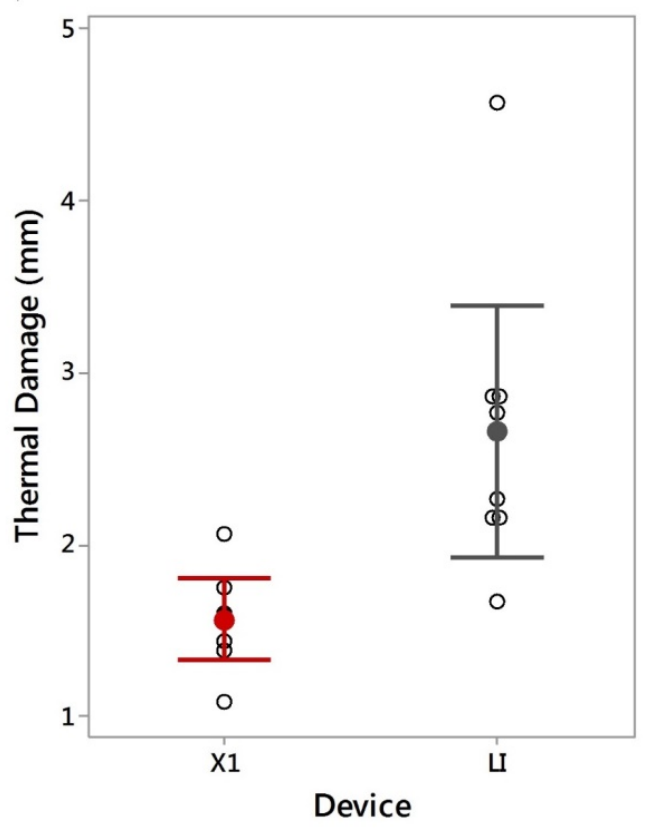

Figure 4. Maximum lateral thermal damage length in carotid artery seals.

\section{Discussion}

The previous version of Enseal has proven to be useful for sealing and transection in a wide variety of procedures and vessel types including thyroidectomy [2], pulmonary artery [3], colorectal [4], hysterectomy [5], and appendectomy [6]. However, feedback from surgeons revealed that design changes could be made to improve the ergonomics and usability of the device. Ethnographic studies were used to ensure that X1 could be operated using one hand by $95 \%$ of all male and female hands $[7,8]$. Each control is within a comfortable range for each digit (Table 4). In contrast to LI, the shaft of the X1 can be rotated using only one finger and can be rotated a full $360^{\circ}$. This complete shaft rotation of X1 improves access to targeted tissue and hard-to-reach anatomy for better surgical efficiency.

It has been known since the 1960's that compression and heat are critical to reliable vessel sealing [9]. It is also known that too much or too little heat and compression will produce unreliable seals [10]. In this regard, tissue impedance serves as a vital determinant of seal formation that can be monitored to ensure seals are reliably made with a high degree of certainty and lateral damage is as minimal as possible.

Ohm's law states that voltage is the product of the current and the resistance, which in alternating current circuits is generalized as the impedance. Hence the local tissue impedance can be continuously monitored by simultaneously measuring voltage and current. As is the case with all electrosurgical devices, current flow through the tissue causes the temperature to rise as electrical energy is dissipated, and the resulting water vaporization and desiccation lead to an increase in tissue impedance. As the impedance of the target tissue increases, current tends to take the path of least resistance through non-desiccated tissue outside the jaws and this may produce a wider region of thermal damage.

The generator for $\mathrm{X} 1$ provides efficient delivery of energy as evidenced in this study by high rates of sealing and hemostasis with low levels of thermal damage and temperature elevations. Throughout the activation cycle, the X1 system dynamically adjusts energy delivery based upon tissue monitoring feedback to the generator. Adaptive Tissue Technology delivers the therapeutic energy and provides audible confirmation of a complete sealing cycle. Upon ceasing radiofrequency energy delivery, a unique end tone and message on the interface screen is presented to confirm that the cycle is complete. Thus, Adaptive Tissue Technology is responsible for the secure sealing, lower jaw temperatures and significantly lower thermal damage observed with X1.

The X1 electrode surface has a larger uninterrupted area $(0.66 \mathrm{~mm}$ greater) beyond the knife slot than LI. This area provides for a larger 


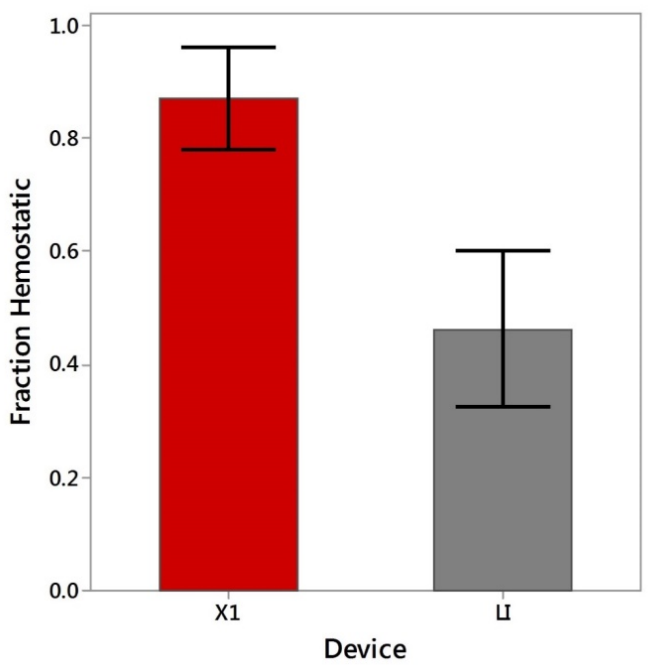

Figure 5. Hemostasis at the distal tip of the device during thick mesentery application.

sealing surface in an area where the tissue is under significant tension while being approximated together by the jaws. The non-conductive spacer on LI occupies a significant portion of the distal tip sealing zone which blocks the flow of electricity and may lead to higher rates of distal tip bleeding in the base mesentery.

Both devices provide median ex vivo burst pressures of sealed vessels that are several times greater than physiological pressures, and high rates of effective hemostatic sealing in vivo both at first pass and after simulated hypertensive crisis, both acutely and after a 30-day survival period. Clinical studies will provide evidence on whether the benefits observed with X1, such as less thermal damage and better hemostasis at the distal tip of the effector, carry over to actual practice.

\section{References}

1. Grochola LF, Vonlanthen R (2016) Surgical Energy Devices or Devices for Hemostasis Atlas of Upper Gastrointestinal and Hepato-Pancreato-Biliary Surgery. Springer Pp: $37-44$.

2. Chavez KV, Barajas EM, Ramírez J (2017) Comparative analysis between a bipolar vessel sealing and cutting device and the tie and suture technique in thyroidectomy: a randomized clinical trial. Surgery 161: 477-484.

3. Yamada T, Sowa T, Bando T, Date H (2016) Experimental study in pulmonary artery sealing with a vessel-sealing device. Asian Cardiovas Thoracic Annals 24: 562-567.

4. Pai A, Sugrue J, Bibi S (2016) Safety and efficacy of an electrothermal bipolar vessel sealing device in sealing and division of the inferior mesenteric vessels in minimally invasive colorectal surgery. Techniques in Coloproctology 20: 505-506.

5. Hun C (2016) Single-Port Retroperitoneal Hysterectomy with EnSeal. Journal of Laparoendoscopic \& Advanced Surgical Techniques and Part B. Videoscopy.

6. Gündüz UR, Karakoyun R, Özdemir Ş, ÇalıŞ H, Habibi M, et al. (2015) The feasibility of bipolar tissue sealer for appendix stump closure. Minim Invas Ther Allied Technol 24: $377-380$.

7. Kouchi M, Yokoyama K, Yamashita J (1994) Human body dimensions data for ergonomic design. Report of National Instit of Biosci Human-Technol 2: 1.

8. Peebles L, Norris B (1998) Adultdata: the handbook of adult anthropometric and strength measurements: data for design safety. Department of Trade and Industry London.

9. Sigel B, Dunn M (1965) The mechanism of blood vessel closure by high frequency electrocoagulation. Surg Gynecol Obestrics 121: 823-831.

10. Wallwiener CW, Rajab TK, Zubke W (2008) Thermal conduction, compression, and electrical current-an evaluation of major parameters of electrosurgical vessel sealing in a porcine in vitro model. J Minim Invas Gynecol 15: 605-610.

Copyright: (C2017 Mootoo M. This is an open-access article distributed under the terms of the Creative Commons Attribution License, which permits unrestricted use, distribution, and reproduction in any medium, provided the original author and source are credited. 